\title{
Educação: tecnologias, cultura hacker e ensino de artes
}

\author{
Juliano Casimiro de Camargo Sampaio' (1)
}

\section{RESUMO}

Este artigo, de natureza teórica, reflete sobre como a aproximação crítica com as tecnologias e com a cultura hacker no espaço escolar pode colaborar para avanços no ensino das artes. $\mathrm{O}$ texto se subdivide em três partes que abordam: noções de tecnologia na educação e suas implicações para as práticas de ensino; cultura hacker e condutas mediadoras de professoras/es em sala de aula; implicações das discussões anteriores para as artes contemporâneas no contexto escolar. Resulta dessa reflexão: em arte, apoiando-nos na história, só a feitura e a fruição são capazes de instaurar processos de construção e ampliação do conhecimento estético; quem cria deve ser visto e incentivado como um agente crítico dos meios, das técnicas, das tecnologias e dos temas com que opera sua criação; a criação, em arte, deve primeiro servir para que a pessoa que cria possa questionar a si, suas relações e seus posicionamentos no mundo, antes que possa propor algo dessa natureza ao fruidor.

PALAVRAS-CHAVE

educação; tecnologias; cultura hacker; ensino de artes.

'Universidade Federal do Tocantins, Palmas, Tocantins, Brasil. 


\title{
EDUCATION: TECHNOLOGY, CULTURE HACKING \& ART TEACHING
}

\begin{abstract}
This article, of a theoretical nature, reflects on how the critical approach with the technologies and the hacker culture in the school space can collaborate to advances in the teaching of the arts. The text is subdivided into three parts that address: notions of technology in education and its implications for teaching practices; hacker culture and conducting mediation of teachers in the classroom; implications of previous discussions for contemporary arts in the school context. Resulting from this reflection: in arts, supported by history, only the making and the enjoyment are capable of establishing processes of construction and expansion of aesthetic knowledge; those who create must be seen and encouraged as a critical agent of the means, techniques, technologies, and themes with which their creation operates; creation, in art, must first serve so that the creators can question themselves and their relationships and positions in the world, before they can propose something of this nature to the user.
\end{abstract}

KEYWORDS

education; technologies; hacker culture; arts teaching.

\section{EDUCACION: TECNOLOGÍA, CULTURA HACKING Y ENSEÑANZA DE LAS ARTES}

\section{RESUMEN}

Este artículo, de carácter teórico, reflexiona sobre cómo el enfoque crítico con las tecnologías y la cultura hacker en el espacio escolar puede colaborar para avanzar en la enseñanza de las artes. El texto se divide en tres partes que abordan: las nociones de tecnología en la educación y sus implicaciones para las prácticas docentes; cultura hacker y conducta de mediadores en el aula; implicaciones de discusiones previas para las artes contemporáneas en el contexto escolar. Resulta de esta reflexión: en el arte, apoyado por la historia, solo la creación y el disfrute son capaces de establecer procesos de construcción y expansión del conocimiento estético; los que crean deben ser vistos y alentados como agentes críticos de los medios, técnicas, tecnologías y temas con los que opera su creación; la creación en el arte debe servir primero para que la persona que crea pueda cuestionarse a sí mismo, sus relaciones y posiciones en el mundo, antes de que pueda proponer algo de esta naturaleza al usuario.

PALABRAS-CLAVE

educación; tecnologías; cultura hacker; enseñanza de las artes. 


\section{EDUCAÇÃO E TECNOLOGIAS: PRIMEIRAS PALAVRAS}

Ao pensarmos relações (aproximações, cruzamentos e distanciamentos) entre educação e tecnologias, criamos, muitas vezes, a ilusão de que tecnologias são apenas as formas mais atuais de relação homem-mundo, geralmente intermediada por máquinas e bastante associada às mídias digitais e à internet. Entretanto, não devemos perder de vista que as tecnologias, da informação e da comunicação (TICs), bem como da inteligência, por exemplo, são muito mais antigas do que a internet. Talvez o equívoco maior e mais frequente esteja em associarmos tecnologia a um tipo específico de mídia. No caso da educação, o giz e a lousa, os livros, a fala e as gesticulações, os materiais disparadores para criação, são igualmente tecnologias, nesse caso, da inteligência (Lévy, 1993). Nesse sentido, é necessário considerarmos as duas dimensões indissociáveis das tecnologias na educação: objeto de estudo e ferramenta pedagógica (Belloni, 2008). Como afirma a autora, devemos considerar que as relações entre pessoas e tecnologias são sempre referidas ao meio social; a forma como promovem socialização, mas também como as tecnologias são recebidas nos grupos de convívio, implica transformações nos modos como cada pessoa elabora suas representações (imagens) sobre as tecnologias.

Para que se compreenda melhor o nosso argumento, vamos recorrer às quatro definições de tecnologia propostas por Vieira Pinto (2005):

- tecnologia como logos da técnica ou epistemologia da técnica;

- tecnologia como sinônimo de técnica;

- tecnologia no sentido de conjunto de todas as técnicas de que dispõe determinada sociedade;

- tecnologia como ideologização da técnica/da máquina ${ }^{1}$.

No primeiro caso, da tecnologia como logos da técnica ou epistemologia da técnica, segundo Costa e Silva (2013), desde Vieira Pinto (2005), a tecnologia é vista como a reflexão que emerge dos e nos modos de se produzir algo. Ou seja, ela é a ciência da técnica. Por essa via, a tecnologia se configura como um conjunto mais ou menos articulado de reflexão sobre os meios de produção e criação. Decorre dessa perspectiva que as tecnologias na educação deveriam se estabelecer como campo de reflexões e críticas a respeito dos percursos relacionais entre professoras/es e estudantes na construção de conhecimentos em rede sobre e para o mundo em que se vive. Assumiríamos, assim, técnicas, mídias e máquinas como objetos de estudo.

$\mathrm{Na}$ segunda perspectiva proposta por Vieira Pinto (2005), tecnologia como técnica, a tecnologia é confundida com a própria técnica. Cada técnica diferente é vista como tecnologia em si mesma. Essa ideia de tecnologia fragmenta a experiên-

1 Ainda que saibamos que essas proposições de Vieira Pinto (2005) sejam já amplamente conhecidas por quem trabalha e estuda as tecnologias e suas relações com a educação, acreditamos que tais leituras não sejam tão frequentes para professoras/es de artes, a quem este texto se direciona prioritariamente. Por essa razão, dedicamos esta primeira parte do texto para que as/os leitoras/es não familiarizados com a temática possam acompanhar nossa argumentação. 
cia de produção humana e institui comparações excludentes. Essa fragmentação impede que se construam reflexões mais profundas a respeito das relações entre técnicas, pessoas e mundo.

Já a tecnologia como o conjunto de técnicas, ainda que diretamente vinculada à ideia anterior, que confunde técnica com tecnologia, volta-se para o conjunto das técnicas de que dispõe uma comunidade em dado período histórico (Vieira Pinto, 2005). Nesse caso, tecnologia é tomada como aspecto geral e, de certa forma, global das produções humanas. E a comparação que se estabelece, a partir de então, não é mais de natureza excludente, ou esta tecnologia ou aquela, mas sim da ordem de hierarquias: sociedades mais ou menos tecnológicas. A tecnologia se configura, portanto, como campo de poder para relações sociais e políticas, sobre as quais a tecnologia como ciência deverá refletir e estabelecer pensamento crítico. Nessa acepção do termo, não é a eficiência do conjunto de técnicas em relação aos objetivos e contextos que interessa, mas sim o uso de meios cada vez mais desenvolvidos cientificamente. A formação instrumental para o uso de tecnologias nesse sentido desconsidera tanto as finalidades educacionais contextuais em si como as diferentes possibilidades de desenvolvimento metodológico dos encontros entre professoras/ es e estudantes bem como não se volta para as tecnologias como objetos de estudo, mantendo-a no âmbito da instrumentalização para outras aprendizagens.

A quarta definição de tecnologia, tecnologia como ideologização da técnica, supõe que as máquinas, quando associadas aos mais modernos meios de comunicação, deixam de ser instrumentos para algo e passam a ser fontes de adoração (Vieira Pinto, 2005). A ideologização da técnica como tecnologia leva à crença inocente de que a máquina poderia resolver todos os problemas da vida humana e, por isso, seria responsável pelo estabelecimento de padrões de felicidade nunca antes alcançados. Cria-se, com isso, o chamado tecnicismo. E não é a técnica (tecnologia) que deve ser evitada, mas sim (e exatamente) o tecnicismo, ou seja, a submissão cega e irresponsável do homem ao domínio das máquinas por ele mesmo criadas (Gentilini, 2013).

Voltemos à primeira das definições de tecnologia, ciência da técnica. Quando a reflexão crítica e histórica que sustenta essa noção de tecnologia ocupa lugar periférico nas relações entre tecnologia e educação, as escolas acabam por não oferecer suporte às crianças e aos jovens para que ampliem os modos de apropriação crítica das redes, das máquinas, dos meios de informação e comunicação, em relação aos seus aspectos técnicos e simbólicos (Belloni, 2008). Não há como ignorar que, ao longo do tempo, as diferentes mídias estabelecem formas de interação pessoa-pessoa e pessoa-mundo bastante peculiares.

A título de exemplo, as tecnologias digitais que se valem da internet alteram substancialmente as relações comunicacionais de um-para-um e de um-para-muitos para o tipo muitos-para-muitos (Kin, 2004). Daí derivam formas de construção semiótica que são características específicas desse tipo de interação. Passa-se a produzir, veicular e acessar informações desde a experiência multimodal, que exige leitura e análise semiótica igualmente multimodal (Kenway, 2000). Nesse sentido, o acesso vertiginoso à informação não garante capacidade de construção de conhecimento desde essa experiência mista (multimodal), e isso precisa ser considerado por professoras/es em suas propostas de relação entre sala de aula e tecnologias. Perguntas 
tais como quem e por que cria/produz/escreve/veicula? Qual a relação contextual do que se lê/vê/ouve com o que se vive (off-line)? Que tipos de conhecimentos estão presentes em uma informação e a que eles servem?, são essenciais na instauração de uma aproximação crítica em relação às mídias e às tecnologias.

Vale lembrar que são os sistemas semióticos que nos permitem organizar o mundo e a nós mesmos (Lévy, 1993). Ou seja, novas construções semióticas introduzidas ou potencializadas por técnicas específicas e por tecnologias, no sentido do conjunto das técnicas, compreendem revisões e reorganizações dos modos pessoais e coletivos de se estar no mundo e de o operar (Brescia, Costa e Tuly, 2013), e, portanto, precisam ganhar ênfase nos processos de formação das pessoas (no nosso caso, no âmbito escolar).

A presença de diferentes mídias e conjuntos de técnicas, como instrumentos didáticos, afeta e reorganiza metodologias de ensino, relações entre professoras/ es, estudantes e conteúdos, níveis de experiência da presença e da relação entre particular e geral (Perez e Silva, 2013). Já a assunção da necessidade de tomar as tecnologias como objetos de estudo, como ciência a ser investigada, oferece a estudantes (e professoras/es) outros caminhos de apropriação das mídias, técnicas e máquinas que não aqueles já presentes em seus cotidianos. E podem, inclusive, evidenciar quando e como conjuntos de técnicas (terceira acepção apresentada neste texto para tecnologia) se tornam meios de dominação e hierarquização social, política e cultural.

Dessa maneira, a reflexão que as tecnologias como objetos de estudo instauram é sobre o conjunto de transformações e implicações sociais que certos usos de determinadas técnicas, máquinas e mídias produzem. Em certo sentido, significa adentrar, explorar e compreender como culturas emergentes, derivadas das tecnologias, tais como a cibercultura, se fazem presentes e influentes nos cotidianos dos envolvidos. De fato, a cibercultura, por exemplo, não se institui como operação humana do mundo online. Ao contrário, ela se institui pelas repercussões do universo das redes e pelas conexões no conjunto de fenômenos sociais da vida da pessoa (Manovich, 2005).

Talvez um dos mais expressivos fenômenos de transformação social derivados da inserção de tecnologias na vida cotidiana da nossa atualidade tenha sido aquele proporcionado pela cibernética. Nossos corpos, cada vez mais, são constituídos, vividos e pensados em conjunção e continuidade com máquinas. Se em alguns casos essa conjunção pode gerar ganhos significativos para a vida humana, em outros ela pode proporcionar e até incentivar uma adesão cega à tecnologia, como se garantisse a capacidade humana de lidar com qualquer intempérie (ideologização da técnica). Por outro lado, pode-se igualmente produzir, por falta de reflexão adequada, certa incapacidade de se criar sistemas semióticos que deem conta de desmistificar a dimensão ciborgue que os corpos apresentam na sociedade a nós contemporânea (Kin, 2004) e que servem de alicerce para parte da criação artística contemporânea, de modo a se chegar à rejeição absoluta da tecnologia (como se isso fosse praticável).

A partir dessa perspectiva, a aproximação crítica de professoras/es e estudantes em relação às tecnologias, também como ferramentas pedagógicas, mas prioritariamente como objetos de estudo, poderá ser considerada coerente com 
processos formativos transformadores de cotidianos e subjetividades e produtores de capacidades de novas construções e leituras semióticas (multimodais) quando atender a três princípios:

- mudanças quantificáveis entre o antes e o depois de seus usos e estudos;

- mudanças nas crenças e nos valores; ou seja, adequação dos resultados às expectativas pessoais e abertura para outras formas de interação com o mundo;

- mudanças qualitativas nas condições sociais de vida da população-alvo, dos participantes, dos executores (Perez e Silva, 2013).

Em suma, os profissionais da educação precisam pensar/praticar a relação entre educação e tecnologias de modo culturalmente inteligente e, antes de qualquer coisa e como finalidade principal, de maneira socialmente responsável (Kenway, 2000). Tal posicionamento exigirá de todos nós, como conjunto social regulador das práticas cotidianas, e de cada um, como agente social particularizado, uso da tecnologia pautado pela crítica e pela criatividade (Bonatto, Silva e Lisboa, 2013).

\section{EDUCAÇÃO E CULTURA HACKER: APROFUNDANDO A RELAÇÃO COM AS TECNOLOGIAS}

$\mathrm{Na}$ direção do que apresentamos no tópico anterior, podemos afirmar que vivemos na Idade Mídia, entendida como a proliferação das produções visuais, hipertextuais e digitais cotidianas (Lobato, 2013), a que Castells (2013) chama de Era da Informação. Mídias e tecnologias na nossa contemporaneidade, de certa forma, estão bastante voltadas para a exposição em larga escala da vida humana (nas redes de comunicação em massa). Além da exposição acelerada de nossas vidas cotidianas e das coisas que acontecem no mundo (informações), a Idade Mídia (em clara referência à Idade Média) nos gera uma sensação de desconforto, na medida em que não nos é ensinado (na escola, por exemplo) a lidar com tamanha exposição e tampouco filtrar, articular e converter as informações em conhecimentos. Considerando essa desenfreada e vertiginosa exposição das pessoas (e também de suas próprias vidas) às informações, talvez a escola pudesse criar/exercitar estratégias para preparar as subjetividades para serem capazes de aprimorar meios de realizar tessituras de conhecimentos em rede (Sibilia,2012). Vale ressaltar, de acordo com o que aponta a autora, que, sob o prisma historiográfico, a instituição escola pode ser tomada como tecnologia: um dispositivo para produzir algo (pessoas), desde uma matriz de convívio cotidiano anterior ao que temos hoje no mundo. Ou seja, o que hoje denominamos por escola é uma tecnologia de época que precisa ser repensada para que possa atender a demandas mais atuais a que estamos expostos.

Em síntese, as mídias digitais passaram a ser usadas de modo acelerado sem que a formação para tal uso acompanhasse o mesmo ritmo. As tecnologias digitais, a exemplo dessa situação, instauram formas de comunicação que direta ou indiretamente se associam às nossas outras formas de comunicação (mais antigas) e desde essa rede relacional não excludente é que alteram nossos modos de agir no mundo (Conte e Devechi, 2016), independentemente de nos debruçarmos ou não 
sobre esse processo para refletir sobre ele. Parece-nos mais coerente e prudente, se não podemos evitá-lo, que nos apropriemos dele de maneira crítica.

Se o domínio das mídias volta seus interesses para os objetos e artefatos que o desenvolvimento tecnológico propicia, os fenômenos sociais decorrentes dos usos da internet e de outras comunicações em rede instauram o que se convencionou chamar de cibercultura (Manovich, 2005). Para Bonilla e Pretto (2015), muitas das tecnologias da informação e da comunicação (TICs), fundantes da cibercultura, em especial aquelas vinculadas à internet, têm permitido repensar a ideia de globalização inexorável, na direção de movimentos que tomam coletividades e grupalidades específicas e a colaboração (tessitura de conhecimentos em rede) como focos, em direção à pluralidade de globalizações possíveis, muito em função da organização e expansão da cultura hacker.

Ainda que já nos anos de 1970 a microinformática, cujo lema era computadores (microcomputadores) para todos, tenha provocado significativos impactos nos modos de se viver em sociedade (Lemos, 2015), é nos anos 1980 que os movimentos na direção do acesso livre às informações e à criação de conhecimentos em rede se instauram de maneira mais efetiva, aspecto fundamental para se pensar a educação nos dias atuais. Uma das principais ações nessa direção é a possibilidade de substituição do sistema copyright, largamente usado no mercado digital, no âmbito da cultura tecnomeritocrática, pelo copyleft (Castells, 2013). Em resumo, o copyleft compreende um regime coletivo de uso de softwares que, na medida em que são melhorados pelos usuários, precisam ser disponibilizados gratuitamente às comunidades interessadas, para que se iniciem outros ciclos de adaptação e melhorias. Em suma, o movimento Software Livre, a que se vincula o copyleft, compreende quatro liberdades: uso, cópia, modificação e redistribuição (Silveira, 2004). Nesse sentido, o conhecimento tecido em rede não se nos apresenta como um processo linear. Diferentes usuários podem partir de um mesmo software, por exemplo, e chegar a diversos tipos de melhorias para diferentes contextos de uso. Assim, um mesmo disparador gera conhecimentos simultâneos e não idênticos entre si, mas de igual valia para os avanços na e da área bem como das vidas das pessoas.

O movimento Software Livre, nessa direção, caracteriza-se como um movimento social que se situa no plano político, ao buscar a democratização do acesso e da produção de tecnologias e de conhecimentos em rede (Veloso, Bonilla e Pretto, 2016), aspecto que deveria ser valorizado e buscado nos ambientes educacionais. Mas, para que a democratização da produção de mídias e meios de comunicação em rede seja tão eficiente como a democratização do acesso à informação, é necessário pensar estratégias de capacitação das pessoas para lidarem, por exemplo, com a linguagem da programação, para que sejam verdadeiramente integradas à rede de cocriação dos meios digitais e computacionais propostos desde a cultura hacker (Silveira, 2004). As linguagens computacionais, assim como as linguagens artísticas, são modos de mediar as nossas experiências no mundo. São operadores passíveis de se desenvolver em múltiplas direções para nos auxiliar a criar modos atualizados de estar no mundo.

Para tanto, a escola precisa se aproximar das tecnologias digitais, da informação e da comunicação, bem como das artes, como objetos de estudo, e não somente 
como instrumentos didáticos. Ou seja, faz-se necessário, no ambiente escolar, que diferenciemos o consumo e o uso utilitário das tecnologias de seu uso consciente, crítico e transformador (Bonilla e Pretto, 2015), avaliando como a vida online impacta a vida off-line e vice-versa. Além disso, devemos repensar a linearidade dos processos de construção de conhecimento, assumidos na maioria dos espaços escolares como a verdadeira forma de conhecer as coisas, a si e ao mundo, no sentido da multidirecionalidade do conhecimento proposta pela cultura hacker. Ou seja, a educação escolar pode aprender com a cultura hacker a incentivar construção de conhecimento em rede a partir de três aspectos fundamentais:

- descentralização e multidirecionalidade das interações;

- criação de protocolos de comunicação abertos e passíveis de revisão e mudança;

- gestão colaborativa dos processos (Castells, 2013), que a nós parecem essenciais para se pensar também as relações entre escola e arte, de que trataremos no terceiro tópico deste texto.

Já podemos encontrar, na esteira do que expusemos sobre a cultura hacker, inciativas no âmbito da educação: os chamados Recursos Educacionais Abertos (REA) - tecnologias voltadas para o ensino e para a aprendizagem - , que podem ser usados, explorados e transformados tanto por estudantes como por professoras/ es, ou mesmo pela comunidade escolar em geral, de modo gratuito (Bonilla e Pretto, 2015). Ou seja, a partir do uso consciente e transformador das tecnologias, as/os estudantes não se configuram mais apenas como consumidores, mas também como coprodutores dos meios de se conhecer e dos saberes que constroem. Nessa direção, as ações das/os estudantes devem ser propiciadas e incentivadas no sentido da produção, criação, crítica, expressão e proposição de práticas pedagógicas coerentes com seus contextos e, em algum aspecto, inovadoras para os fins que pretendem (Veloso, Bonilla e Pretto, 2016).

Não devemos perder de vista que tais proposições só se tornam possíveis diante da existência de condições técnicas e de conectividade adequadas para acessar, investigar, remixar e reordenar informações, em prol da aproximação crítica e socialmente responsável, para a criação de conhecimentos em rede que sejam, ao mesmo tempo, de grande valia para as pessoas envolvidas e para as sociedades que as circundam (Veloso, Bonilla e Pretto, 2016). As reflexões (no ambiente escolar) sobre o uso socialmente responsável das tecnologias devem considerar que nelas estão implicadas três dimensões interdependentes de sua aplicabilidade:

- uso estratégico, geralmente de natureza governamental e empresarial;

- uso retórico, para a construção de discursos propagandísticos, políticos e comunitários;

- uso cotidiano, de que se esperam os usos discrepantes e renovadores da própria tecnologia (Lemos, 2015).

Para finalizar nossa exposição deste segundo tópico, um aspecto merece destaque no que estamos construindo até aqui como argumento. Auxiliar a/o estudante a lidar com a vertiginosa presença de informações em seu cotidiano e propiciar 
que ela/e se perceba como cocriador(a), tanto dos meios de se conhecer como dos conhecimentos derivados das redes que estabelece, é, em certa medida, potencializar a passagem do processo de informatização da informação (Era da Informação) para a associação, a negociação e a reorganização da informação em relação aos sentidos afetivos e cognitivos que a pessoa já tem acerca de si e do mundo, em direção a novos sentidos que lhe sirvam a mudanças efetivas de posturas em relação a si e a esse mesmo mundo (Bonatto, Silva e Lisboa, 2013). Essa transformação dos cotidianos depende muito da passagem da informação para a ação (Castells, 2013) e da capacidade de se lidar com leituras não lineares do mundo, presentes, por exemplo, nas informações hipertextuais, bastante comuns nos trânsitos online e nas artes a nós contemporâneas.

O hipertexto é uma forma de "escrita" que mistura palavras, sons e imagens e permite que endereçamentos variados emerjam de um mesmo ponto inicial de acesso, por meio de diferentes links (Lemos, 2015). Desse modo, como já apontamos, não há como assumir linearidade na construção de conhecimentos online, do mesmo modo que não deveríamos assumir tal linearidade na tessitura de conhecimentos no mundo off-line. Trata-se, primeiramente, de diferentes linhas que representam a um só instante:

- caminhos possíveis de serem percorridos pela pessoa;

- exercícios pessoais de seletividade;

- circularidade das informações, visto que podem sempre remeter a um ponto já acessado pela pessoa em momento anterior;

- criação e compartilhamento de informações ainda não disponibilizadas para que outros usuários possam se valer delas.

Ou seja, a experiência de endereçamentos dos hipertextos exige da pessoa lidar com uma natureza de plasticidade da informação, bastante característica da vida online (Bonatto, Silva e Lisboa, 2013), ainda que não exclusiva dela. Assim, os hipertextos propiciam uma relação com o mundo a partir de estados de atenção-navegação-interação (Lemos, 2015) que fazem das pessoas autoras de seus próprios percursos de construção de conhecimento e produtoras de informações. Entretanto, a flexibilidade que as redes hipertextuais produzem exige de maneira intensa que se consiga concentrar recursos e coordenar atividades para fins específicos (Castells, 2013), função crucial da/o professor(a) mediador(a) dos processos de construção de conhecimento articulados a um só momento à vida online e à vida off-line.

Em suma, a cultura hacker ensina à educação que:

- conhecimentos não se dão por processos lineares e passíveis de reprodução;

- a transformação da informação em conhecimento depende da passagem daquela à ação;

- cada um é autor de seu próprio percurso de tessitura de saberes e, ao mesmo, tempo responsável por propiciar aos outros que eles possam ter materiais suficientes para também construir seus caminhos pessoais de lidar com o mundo; 
- novos modos de escrita (hipertextos) produzem a necessidade de novos modos de leitura do mundo;

- a vida online não é desvinculada da vida off-line.

\section{EDUCAÇÃO: ENTRE ARTES E TECNOLOGIAS}

Neste tópico, mais detidamente sobre as relações entre arte e tecnologia na educação, devemos considerar que, costumeiramente, a ideia que temos hoje no Ocidente do que vem a ser arte está bastante atrelada à noção que se forjou no Renascimento, com o desvínculo da arte de seu antigo caráter religioso e ritualístico, muito em função da codificação dos sistemas artísticos visuais (Santaella, 2005). Na nossa contemporaneidade, expressiva parcela dos nossos repertórios mnemônicos, a partir do que opinamos e de como agimos nas sociedades em que vivemos, é oriunda dos programas visuais construídos e sustentados pela TV, pelo cinema (Almeida, 1999) e por vertiginosa circulação de informações na internet. São esses os contextos, os veículos e as tecnologias que estabelecem de modo majoritário os objetos culturais e bens simbólicos a partir dos quais produzimos, reproduzimos e dissolvemos realidades, bem como os modos de nos posicionarmos em relação a eles (Larrosa, 2015).

As lembranças são, por essa perspectiva, signos linguísticos (visuais e sonoros) que inscrevem na carne da pessoa as perspectivas sobre as quais ela olha o mundo e pode supor (ou não) mundos diferentes (Pasolini, 1990). Tal linguagem (proveniente das experiências mnemônicas advindas das visualidades do mundo, mas não só delas) é mais do que um conjunto convencional de signos, ela é o modo original e primário de experimentarmos o mundo, desde uma dimensão não racionalista (Larrosa, 2015). Isso porque, antes de qualquer ação da inteligência, as coisas do mundo, com suas linguagens próprias, produzem em nós inclinações não verbais de interação (Pasolini, 1990).

Desse modo, o significado que atribuímos às coisas (imagens do mundo) não se encontra nas próprias coisas, senão nas leituras que fazemos delas desde aquilo que somos capazes de acessar e de se deixar interpelar das linguagens que as constituem (Sgarbi, 2001) e das linguagens que usamos para mediar nossas experiências no mundo. É essa linguagem das coisas que nos convoca a certos modos de relação com elas. Evidentemente, de nossa parte, aceitamos e recusamos (conscientes ou não disso) diversos desses convites e tendemos a nos aproximar das coisas sempre por um mesmo campo linguístico e esforço sensório-motor. Tal fato limita nossas possibilidades de "ouvir" as coisas com maior amplitude e fazer da relação sempre renovada com e demandada pelas coisas do mundo modos de alterar nossos estados de presença. Devemos considerar ainda que a linguagem primitiva das coisas a partir do que criamos nossas imagens visuais da memória e nossa sensorialidade/ sensibilidade se nos apresenta de modo desarticulado, cujo exercício de articulação é realizado subjetivamente diante da cultura em que nos inserimos (Pasolini, 1990) e em instituições tais como a escola.

É pelo exercício das diversas linguagens a que nós temos acesso, de modo às vezes mais isolado, ainda que na maioria das vezes de maneira articulada, que conseguimos ampliar o escopo das relações que se nos tornam possíveis a respeito 
das coisas do mundo. Afinal, nenhuma das linguagens é capaz de dizer toda a experiência do cotidiano, tampouco mediar para nós todas elas, e as tessituras de conhecimento que a partir dele são tramadas. De maneira semelhante, a associação de todas elas (linguagens) não daria conta dessa tarefa hercúlea, independentemente de seus meios, suas técnicas e/ou suas tecnologias.

Contudo, o problema mais relevante se centra na constante fixação de modos de comunicação e linguagem, a partir de perspectivas hegemônicas, sobre como devem ser: a construção de discursos; e as práticas políticas e sociais, caracteristicamente (na maioria dos casos) excludentes e hierarquizantes, para se lidar com o mundo (Sgarbi, 2001). Nessa direção, à escola caberia um importante papel: auxiliar as pessoas a serem capazes de se utilizar de diferentes linguagens para comunicar, refletir, aderir e recusar os significados culturalmente validados, para que possamos desbravar novos e mais frutíferos caminhos de relação eu-outro-mundo. Ao contrário desse movimento de fixação de significados e modos de aproximação entre a pessoa e o mundo, reiteramos, as coisas no mundo se constituem como diferentes linguagens que nos interpelam de diferentes maneiras (a cada vez que com elas interagimos) e nos convidam a dialogar com elas sempre diversamente e desde naturezas comunicacionais e interativas variadas (Hillman, 1993).

$\mathrm{Na}$ direção desse exercício variado de linguagens para tentar adentrar as tramas do mundo, podemos considerar a poesia (como modo de relação pessoa-outro-mundo) não como um gênero, mas como uma forma de consciência sobre o mundo. A poeticidade como operadora do mundo e dos modos de se estar no mundo não se prende à linearidade das relações e dos conhecimentos. Ao contrário, o raciocínio poético está mais próximo da forma como constituímos nosso pensamento na vida cotidiana. A exemplo das artes, nosso pensamento cotidiano não se centra em superar os problemas, necessariamente, mas em aprender a conviver com eles. Das fraquezas que reconhecemos em nós, nas materialidades e nas pessoas, fazemos emergir resultados (produtos, obras, processos, mudanças) que têm um tanto do nosso desejo, um tanto das fraquezas envolvidas, um tanto das potências que se fazem presentes, um tanto das demandas do mundo e um bom tanto de imprevisibilidade (Tarkovski, 1998).

Desse modo, podemos assumir a educação com artes como um propício exercício pedagógico para auxiliar as pessoas em processos de subjetivação na direção de modos mais humanizados de se lidar com a diferença, com o exercício da política cotidiana e com a alteridade. Nossas escolhas pedagógicas, principalmente em artes, não devem subjetivar na direção da aceitação irrestrita das condições atuais de vida, tampouco para a recusa total das condições de vida, o que, certamente, nos colocaria sob o risco da inadequação do convívio social (Migliorin, 2015). Para tanto, precisamos mais do que educar os sentidos para estarmos conscientes das coisas que se passam no mundo. Precisamos descobrir juntos como propor, percorrer e sustentar novos caminhos, novas rotas, pelas quais nossos sentidos e nossas motricidades possam se relacionar com as coisas do mundo de modos diversos dos ordinários. De um lado, precisamos tomar consciência da nossa mirada sobre o mundo e, de outro, ampliar possibilidades de miradas, caminhos, percursos. A partir desse movimento, nossos modos de estar no mundo e operá-lo se tornam muito mais passíveis de escolhas do que de coerções (Leite e Christofoletti, 2015). 
Quando pensamos a conjunção entre educação, arte e tecnologias, em especial as digitais, da informação e da comunicação, pensamos na possibilidade de ampliar (às vezes instaurar) experiências lúdicas de se experimentar (a si) de modo diverso daquele que se faz diariamente. Isso só será possível se considerarmos e exercitarmos o poder das artes de devolver ao mundo algumas de suas possibilidades de aparição que até aquele momento, da criação, não existiam nos sentidos dos artistas e dos fruidores (Ishaghpour, 2004). Em suma, ao trazer à superfície da relação pessoa-mundo os aspectos até então inacessíveis do mundo e de suas relações, a arte assume posto de questionadora sobre nossa existência: para que vive o homem? A que se deve sua aparição neste planeta? Como ele vive neste mundo? (Tarkovski, 1998). Em suma, a educação deve aceitar que artes e tecnologias constroem meios de permitir à pessoa explicar-se a si mesma, tecer possibilidade de correlação entre si e o mundo. A exemplo dessa afirmação, podemos assumir com Migliorin (2015), a partir de suas experiências com cinema na escola, que educação, arte e tecnologias, juntas, permitem pensar as pedagogias como percursos multidirecionais que tomam os modos de agir, sentir e pensar das pessoas e a (re)constituição de sociedades como suas questões principais, na mesma direção do que expusemos a respeito da cultura hacker.

Diferente do conhecimento fruto das inteligências, o conhecimento estético de que as artes se constituem e para o qual se direcionam é, a cada criação, a totalidade daquilo que o artista consegue conhecer de si e do mundo, desde sua existência sensorial. Acontece que tal totalidade é ilusória e sempre se "quebra" diante da frustração que todas as linguagens trazem ao tentar dizer a experiência em sua completude (Tarkovski, 1998). O exercício de criação e fruição em sala de aula tem aí um ponto de convergência entre arte e vida. Sempre precisaremos de diferentes linguagens para comunicar a experiência e, inclusive, para a significar. Talvez as artes com as tecnologias na escola possam nos auxiliar na criação de condições para reencontrar a vida na vida, deixando de fora (criticamente) tudo que seja representação e interpretação dos fenômenos (que nos dominam antes mesmo da experiência). Tal redução fenomenológica só é possível se a educação, as tecnologias e as artes nos permitirem suspender a vida para olhar para ela criticamente (Ishaghpour, 2004).

Nessa perspectiva, a mudança nas tecnologias digitais, de informação e de comunicação, tem instaurado novas possibilidades de poéticas e de presenças e, desse modo, outros meios de imersão no e emersão do mundo, e, portanto, de maneiras de lidar com os problemas da vida cotidiana. Por exemplo, as realidades virtuais nos permitem experimentar presenças de objetos em tempo real que não se apresentam a nós materialmente, senão pelo único suporte da memória virtual (Maciel, 1996). As poéticas mais contemporâneas a nós, em especial em audiovisual, têm buscado propiciar experiências multissensoriais e de afetação física, com fins de se alterar as relações entre os presentes e as obras, na direção das poéticas do convívio (Moran, 2014), como experiências multimodais, das quais falamos na segunda parte deste texto. Nesse sentido, as tecnologias, no exercício do corpo em artes, tendem a desestabilizar a matriz hegemônica que adota e assume o corpo desde sua perspectiva bioanatômica. Pelas tecnologias, o corpo se vê ampliado, ramificado, e demanda caminhos de se atribuir sentido a essa experiência (Nunes, 2017). Complementarmente, as redes que se instauram mais recentemente vêm 
estabelecendo três diferentes naturezas de poéticas: as da programação, voltadas para softwares para interação e ludicidade (que instauram e reorganizam a cultura hacker); as da navegação, que se valem da vida online como processo artístico (exigindo que se assumam as tecnologias como temas de estudos, na direção do que expusemos na primeira parte deste texto); as dos bancos de dados, que se voltam para como são agrupados, preservados e disponibilizados os dados na rede (Leão, 2005). Há ainda forte apelo àquilo que escapa ao controle do criador nas artes associadas às tecnologias digitais, de informação e de comunicação. $\mathrm{Na}$ fotografia, por exemplo, independentemente de todo o rigor técnico, a imagem fotográfica como que nos convida a ser capturado por aquilo que a imprevisibilidade retira do controle do fotógrafo (Benjamin, 1994), aspecto inegável como presença da vida cotidiana: saber lidar com a poeticidade da imprevisibilidade.

Tantos outros exemplos de conjunção entre educação, arte e tecnologias poderiam ser trazidos a este texto, como exemplos e para discussão. Contudo, independentemente do meio e da linguagem em artes e tecnologias que escolhamos para trabalhar na escola, devemos considerar três aspectos fundamentais:

- em arte, apoiando-nos na história, só a feitura e a fruição são capazes de instaurar processos de construção e ampliação do conhecimento estético (das poéticas de mundo);

- quem cria deve ser visto e incentivado como um agente crítico dos meios, das técnicas, das tecnologias e dos temas com que opera sua criação;

- a criação, em arte, deve primeiro servir para que a pessoa que cria possa se questionar a si, suas relações e seus posicionamentos no mundo, antes que possa propor algo dessa natureza ao fruidor.

\section{REFERÊNCIAS}

ALMEIDA, M. J. A educação visual da memória: imagens agentes do cinema e da televisão. Pró-Posições, v. 10, n. 2(29), p. 9-25, 1999.

BELLONI, M. L. Os jovens e a internet: representações, usos e apropriações. In: FANTIN, M.; GIRARDELLO, G. (org.). Liga, roda, clica: estudos em mídia, cultura e infância. Campinas: Papirus, 2008. p. 99-112.

BENJAMIN, W. Magia e técnica. Arte e Política. São Paulo: Brasiliense, 1994. (Obras Escolhidas).

BONATTO, F. R. de O.; SILVA, A. F.; LISBOA, P. Tecnologias nas atividades escolares: perspectivas e desafios. In: VALLE, L. E. R.; MATTOS, M. J. V. M.; COSTA, J.W. (org.). Educação digital: a tecnologia a favor da inclusão. Porto Alegre: Penso, 2013. p. 58-74.

BONILLA, M. H.; PRETTO, N. Movimento colaborativos, tecnologias digitais e educação. Em Aberto, v. 28, n. 94, p. 23-40, 2015. https://doi.org/10.24109/2176-6673. emaberto.28i94.1666

BRESCIA, A. T.; COSTA, J. W.; TULY, S. P. Redes sociais e suas possibilidades de uso na educação. In: VALLE, L. E. R.; MATTOS, M. J. V. M.; COSTA, J. W. (org.). Educação digital: a tecnologia a favor da inclusão. Porto Alegre: Penso, 2013. p.75-90. 
CASTELLS, M. A galáxia da internet: reflexões sobre a internet, os negócios e a sociedade. Rio de Janeiro: Zahar, 2013.

CONTE, E.; DEVECHI, C. P. V. A experiência estética em tempos de virtualização tecnológica. Cadernos de Pesquisa, v. 46, n. 162, p. 1216-1233, 2016. https://doi. org/10.1590/198053143724

COSTA E SILVA, G. Tecnologia, educação e tecnocentrismo: as contribuições de Álvaro Vieira Pinto. Revista Brasileira de Estudos Pedagógicos, Brasília, v. 94, n. 238, p. 839-857, set./dez. 2013. https://doi.org/10.1590/S2176-66812013000300010 GENTILINI, J. A. Computadores, informática e educação: questões sobre a gestão de programas de inclusão digital no Brasil. In: VALLE, L. E. R.; MATTOS, M. J. V. M.; COSTA, J. W. (org.). Educação digital: a tecnologia a favor da inclusão. Porto Alegre: Penso, 2013. p. 39-57.

HILLMAN, J. Cidade \& alma. São Paulo: Studio Nobel, 1993.

ISHAGHPOUR, Y. Abbas Kiarostami. São Paulo: Cosac Naify, 2004.

KENWAY, J. Educando cibercidadãos que sejam "ligados” e críticos. In: SILVA, L. H. (org.). A escola cidadã no contexto da globalização. Rio de Janeiro: Petrópolis, 2000. p. $99-120$.

KIN, J. H. Cibernética, ciborgues e ciberespaço: notas sobre as origens da cibernética e sua reinvenção cultural. Horizontes Antropológicos, v. 10, n. 21, p. 199-219, 2004. https://doi.org/10.1590/S0104-71832004000100009

LARROSA, J. Pedagogia profana: danças, piruetas e mascaradas. Belo Horizonte: Autêntica, 2015.

LEÃO, L. Poéticas do Ciberespaço. In: LEÃO, L. (org.). O chip e o caleidoscópio: reflexões sobre as novas mídias. São Paulo: Editora SENAC, 2005.

LEITE, C.D.P.; CHRISTOFOLETTI, R. Por que cinema? O que pode o cinema na educação e a educação no cinema. Fronteiras de encontros. In: FRESQUET, A. (org.). Cinema e educação: a Lei 13.006. Ouro Preto: Universo Produções, 2015. p. 40-50.

LEMOS, A. Cibercultura: tecnologia e vida social na cultura contemporânea. Porto Alegre: Sulina, 2015.

LÉVY, P. As tecnologias da inteligência: o futuro do pensamento na era da informática. Rio de Janeiro: 34, 1993.

LOBATO, L. F. Para além da tecnologia, a magia. Revista Brasileira de Estudos da Presença,Porto Alegre,v.3,n.2, p. 633-645,2013.https://doi.org/10.1590/2237-266036896

MACIEL, K. A última imagem. In: PARENTE, A. (org.). Imagem máquina: a era das tecnologias do virtual. Rio de Janeiro: 34, 1996. p. 253-257.

MANOVICH, L. Novas mídias como tecnologia e idéia: dez definições. In: LEÃO, L. (org.). O chip e o caleidoscópio: reflexões sobre as novas mídias. São Paulo: Senac São Paulo, 2005. p. 23-50.

MIGLIORIN, C. Inevitavelmente cinema: educação, política e mafuá. Rio de Janeiro: Beco do Azougue, 2015. 
MORAN, P. A repetição da diferença: jogos entre sons e imagens. In: GONÇALVES, O. (org.). Narrativas sensoriais. Rio de Janeiro: Circuito, 2014. p. 197-208.

NUNES, F. O. Vinicius Dantas e a expansão tecnológica do corpo. Croma, Estudos Artísticos, v. 5, n. 9, p. 34-44, 2017.

PASOLINI, P. P. Os jovens infelizes. Antologia de ensaios corsários. São Paulo: Brasiliense, 1990.

PEREZ, J. R. R.; SILVA, F. de P. Computadores na educação: uma revisão da pesquisa internacional. In: VALLE, L. E. R.; MATTOS, M. J. V. M.; COSTA, J. W. (org.). Educação digital: a tecnologia a favor da inclusão. Porto Alegre: Penso, 2013.p. 21-38. SANTAELLA, L. Panorama da arte tecnológica. In: LEÃO, L. (org.). O chip e o caleidoscópio: reflexões sobre as novas mídias. São Paulo: Senac São Paulo, 2005. p. 247-280.

SGARBI, P. Colando textos, colando imagens. In: ALVES, N.; SGARBI, P. (org.). Espaços e imagens na escola. Rio de Janeiro: DP\&A, 2001. p. 115-132.

SIBILIA, P. Redes ou paredes: a escola em tempos de dispersão. Rio de Janeiro: Contraponto, 2012.

SILVEIRA, S. A. Software livre: a luta pela liberdade do conhecimento. São Paulo: Fundação Perseu Abramo, 2004.

TARKOVSKI, A. Esculpir o tempo. São Paulo: Martins Fontes, 1998.

VELOSO, M. M. S. de A.; BONILLA, M. H. S.; PRETTO, N. de L. A cultura da liberdade de criação e o cerceamento tecnológico e normativo: potencialidades para a autoria na educação. Educação Temática Digital, v. 18, n. 1, p. 43-59, 2016. https:// doi.org/10.20396/etd.v18i1.8639486

VIEIRA PINTO, A. O conceito de tecnologia. Rio de Janeiro: Contraponto, 2005.

\section{SOBRE O AUTOR}

Juliano Casimiro de Camargo Sampaio é doutor em psicologia pela Universidade de São Paulo (USP). Professor da Universidade Federal do Tocantins (UFT).

E-mail: juliano.casimiro@uft.edu.br

Conflitos de interesse: $\mathrm{O}$ autor declara que não possui nenhum interesse comercial ou associativo que represente conflito de interesses em relação ao manuscrito.

Financiamento: $\mathrm{O}$ estudo não recebeu financiamento.

Recebido em 7 de agosto de 2019 Aprovado em 24 de junbo de 2020

(C) 2021 Associação Nacional de Pós-Graduação e Pesquisa em Educação - ANPEd Este é um artigo de acesso aberto distribuído nos termos de licença Creative Commons. 